\title{
Estratégia\&Negócios
}

ISSN 1984-3372

http://www.portaldeperiodicos.unisul.br/index.php/EeN/

\section{A INFLUÊNCIA DA INSTITUIÇÃO NA INTERNACIONALIZAÇÃO DAS VINÍCOLAS NO BRASIL}

\section{INSTITUTION'S INFLUENCE IN THE INTERNATIONALIZATION OF THE WINERIES IN BRAZIL}

\section{Cyntia Vilasboas Calixto}

Universidade do Vale do Rio dos Sinos - UNISINOS

E-mail: cyntiacalixto@gmail.com

\section{Jefferson Marlon Monticelli}

Universidade do Vale do Rio dos Sinos - UNISINOS

E-mail: jeffmarlon@hotmail.com

\section{Ivan Lapuente Garrido}

Universidade do Vale do Rio dos Sinos - UNISINOS

E-mail: igarrido@unisinos.br

\section{Silvio Luis de Vasconcellos}

Universidade do Vale do Rio dos Sinos - UNISINOS

E-mail: silvio@conexo.com.br

Recebido em 20/06/2012. Aprovado em 23/08/2012. Disponibilizado em 01/10/2012.

Avaliado pelo Sistema double blind review

R. eletr. estrat. neg., Florianópolis, v.5, n.2, p.3-27, mai./ago. 2012

http://portaldeperiodicos.unisul.br/index.php/EeN/index

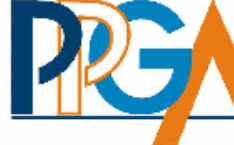

Programa de

Pós-graduação er

ADMINISTRACÃO

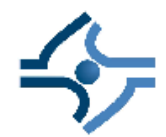

CCopyright 2008 UNISUL-PPGA/Estratégia e Negócios. Todos os direitos reservados. Permitida citação parcial, desde que identificada a fonte. Proibida a reprodução total. Em caso de dúvidas, consulte o editor:

ademar.unisul@gmail.com; (48) 3229-1932. 


\section{RESUMO}

O aumento da competição internacional no mercado de vinhos do Brasil levou as vinícolas brasileiras a questionar sua estratégia e a buscar o mercado externo como alternativa para manter sua competitividade. Este artigo visou a compreender a influência das instituições no processo de internacionalização das vinícolas da Serra Gaúcha. Para tanto, realizou-se um estudo de caso com aplicação de entrevistas semiestruturadas junto aos representantes do Projeto Wines of Brasil e quatro vinícolas associadas ao projeto, além de pesquisa documental. O Projeto Setorial Integrado Wines of Brasil surgiu de uma iniciativa do Instituto Brasileiro do Vinho (IBRAVIN) e da Agência de Promoção à Exportação (APEX) na busca da promoção do vinho brasileiro no exterior. Toda a estrutura institucional desenvolvida propiciou o fomento da internacionalização das vinícolas da região, implicando um maior reconhecimento dos vinhos nacionais, não só no exterior, mas também no Brasil, por meio do aumento do volume de exportações e do número de exportadores envolvidos no negócio. Ao analisar as teorias de internacionalização baseadas nas abordagens comportamental e econômica-racional, percebeu-se que nenhuma era capaz de explicar completamente a ação desenvolvida pelas vinícolas com vistas ao mercado externo, necessitando ampliar o escopo de análise. Todavia, constatou-se a relevância do ambiente institucional em nível nacional para alavancar o processo de internacionalização das vinícolas que aderiram ao projeto, mesmo que estejam presentes limitações nos domínios normativo e regulatório em que os agentes estão inseridos.

Palavras-chave: Internacionalização de empresas. Wines of Brasil. Visão baseada nas instituições.

\section{INTRODUÇÃO}

A literatura sobre o processo de internacionalização das empresas oriundas de países emergentes ainda está em construção, uma vez que o referencial teórico existente está baseado em países industrialmente avançados. Assim, as empresas hoje encaram condições bastante 
distintas daquelas enfrentadas pelas empresas que primeiro se internacionalizaram. Ainda, os governos passaram a agir diretamente no processo de internacionalização, por meio de mecanismos institucionais, buscando desenvolvimento nacional. (FLEURY; FLEURY, 2007).

As empresas das grandes economias emergentes buscam, no processo de internacionalização, uma forma de se proteger das turbulências enfrentadas no mercado doméstico. De acordo com Fleury e Fleury (2007), a internacionalização tardia das empresas brasileiras é resultado de sua dimensão geográfica, que resulta num mercado interno grande, da falta de incentivos do governo, da proteção do mercado doméstico até a década de 1990 e da distância cultural em relação a outros vizinhos. Essas hipóteses são oriundas tanto da literatura econômica (DUNNING, 1988), quanto da comportamental (JOHANSON; VAHLNE, 1977, 1990). Contudo, percebe-se que, na última década, o governo tem direcionado grandes esforços para estimular as empresas brasileiras a atuarem no mercado externo, alterando a dinâmica dos negócios. Ainda assim, o mercado interno altamente aquecido ainda desestimula algumas empresas na diversificação de mercados, uma vez que o custo e o risco são maiores ao operar em ambientes desconhecidos (ROCHA; SILVA; CARNEIRO, 2007).

O Brasil é um país produtor de vinhos desde 1875, com a chegada dos imigrantes italianos no Rio Grande do Sul (WINES OF BRASIL, 2012). Além das regiões tradicionalmente produtoras, como a Serra Gaúcha, consolidam-se outros polos produtores no Rio Grande do Sul, no Vale do Rio São Francisco (entre os estados de Pernambuco e Bahia), no Vale do Rio do Peixe (Santa Catarina), na região leste de São Paulo, no Paraná e em Minas Gerais (IBRAVIN, 2012b).

A indústria vinícola brasileira produziu 352 milhões de litros de vinhos em 2011, dos quais $83,4 \%$ foram vinhos de mesa e apenas $16,6 \%$ foram vinhos finos. O Rio Grande do Sul é o maior produtor brasileiro, representando $87,73 \%$ da produção nacional, seguido de Santa Catarina (7,60\%), São Paulo (1,16\%) e Minas Gerais (1\%) (IBRAVIN, 2012b). Segundo a mesma fonte, os denominados "vinhos de mesa" são elaborados com variedades de uvas não viníferas, conhecidos nacionalmente como os "vinhos de garrafão". Enquanto os "vinhos finos" são aqueles produzidos com uvas vitis viníferas, sendo objeto de esforço de exportação.

Na busca de compreender o processo de internacionalização do setor vitivinícola do Rio Grande do Sul, constatou-se a relevância do Projeto Setorial Integrado chamado Wines of Brasil, que tem, como objetivo principal, promover a qualidade do vinho brasileiro no mercado internacional. Logo, surgiu a seguinte questão de pesquisa: Como os elementos institucionais 
influenciaram as vinícolas associadas ao projeto Wines of Brasil? No intuito de responder a essa questão, buscou-se suporte nas teorias de internacionalização e na visão baseada em instituições, desenvolvida por Mike Peng, em 2002.

Tendo em vista que a produção de vinhos do Rio Grande do Sul é centralizada em quatro regiões: Serra Gaúcha, Serra do Sudeste, Campos de Cima da Serra e Campanha, este trabalho direciona seus esforços na compreensão da influência da instituição no processo de internacionalização das vinícolas da Serra Gaúcha. Especificamente, objetivou-se: a) compreender a estrutura do setor de vitivinicultura do Rio Grande do Sul; b) descrever o processo de internacionalização das vinícolas da Serra Gaúcha com o suporte da literatura acerca de internacionalização de empresas, integrando-a com a visão baseada em instituições; e c) analisar a formação do Projeto Setorial Integrado APEX-IBRAVIN, denominado Wines of Brasil e sua respectiva ação junto aos empresários locais no processo de internacionalização dos vinhos da região.

O artigo é composto por seis seções: após a introdução, apresenta-se o referencial teórico que o amparou. Na terceira seção, desenvolve-se a metodologia utilizada para a realização do estudo. Em seguida, é descrito o caso, a partir das entrevistas realizadas. Posteriormente, as informações são cruzadas, confrontando o campo teórico e o empírico. Na última, estão as considerações finais acerca do que foi proposto.

\section{REFERENCIAL TEÓRICO}

O presente estudo está ancorado nas teorias de negócios internacionais e na visão baseada em instituições. Tais temas estão sendo vinculados a partir dos estudos de Peng, Wang e Jiang (2008), uma vez que os autores enfatizam que é necessário levar em consideração o ambiente institucional para compreender a internacionalização de empresas em países emergentes. 


\subsection{TEORIAS DE INTERNACIONALIZAÇÃO}

O conceito de internacionalização adotado neste artigo refere-se a um processo de crescente envolvimento com operações internacionais, que pode ser caracterizado segundo a sua direção. Conforme Welch e Luostarinen (1988), a internacionalização para dentro (inward) é representada pelos processos de importação, obtenção de licenças ou contratos de franquias de empresas estrangeiras. Por outro lado, a internacionalização para fora (outward) ocorre por meio dos processos de exportação, participação em joint-ventures e investimento direto no exterior.

Apesar de diversas lentes teóricas serem utilizadas a fim de compreender o processo de internacionalização, consolidaram-se duas abordagens: uma de viés econômico-racional e outra de cunho comportamental. A escola econômica possui um viés direcionado à racionalização, por meio da otimização dos custos e dos fatores econômicos envolvidos no processo de internacionalização (COASE, 1937; VERNON, 1966; DUNNING, 1980, 1988). Em contrapartida, a teoria comportamental, originada nos estudos da Escola de Uppsala, aborda o tema com um enfoque baseado no comportamento gradual para internacionalização, levando em consideração aspectos como a distância psíquica e aprendizagem (JOHANSON; WIEDERSHEIM-PAUL, 1975; JOHANSON; VAHLNE, 1977, 1990; BJÖRKMAN; FORSGREN, 2000).

As teorias econômicas de internacionalização têm explicado esse processo por meio do nível agregado de macroeconomia, das indústrias e da firma. A teoria do poder de mercado desenvolvida por Hymer (1960) é um aprimoramento à teoria do portfólio de Markowitz (1952), que considerava a taxa de juros como sendo o fator principal na decisão de escolha da firma sobre o país que deveria internacionalizar-se. De acordo com Hymer, o risco, a incerteza e as barreiras comerciais (imperfeições do mercado) inviabilizam a compreensão do fluxo de capitais pela abordagem da teoria do portfólio.

Na teoria do ciclo de vida do produto, Vernon (1966) constatou o quão relevante era a decisão sobre a localização da produção. De um modo geral, os países mais desenvolvidos lançavam as inovações e as produziam inicialmente para o mercado doméstico e, posteriormente, com a maturação do mercado e a consequente queda de preços, a manufatura poderia ser transferida para países menos desenvolvidos, por meio da padronização e massificação da produção. 
A teoria dos custos de transação foi trabalhada, originalmente, por Coase (1937) e posteriormente desenvolvida por Williamson (1985). Os autores expandiram o foco da firma ao maximizar lucros por intermédio da transferência de recursos para a obtenção de vantagens econômicas de acordo com a estrutura de governança. Conforme Coase (1937), a análise dos custos não está relacionada apenas à atividade produtiva da firma, mas também à coleta de informações, negociação e formação de contratos, visando a garantir o cumprimento do previamente acordado. Para o autor, os mercados falham, sendo necessária a atuação de outras instituições para regulá-los. Já Williamsom (1985) baseia sua análise na racionalidade limitada dos agentes econômicos, na propensão de exercer comportamento oportunista e provocar prejuízos econômicos à outra parte, e na especificidade dos ativos baseada no alto custo intrínseco desenvolvido pela relação de dependência do consumidor em adquiri-lo.

A teoria de internalização proposta por Buckley e Casson (1976) baseia-se na maximização dos lucros em mercados imperfeitos por meio da internalização de certas atividades produtivas pela firma ao invés de delegá-las a outras firmas. Com a contribuição destas teorias, Dunning $(1980 ; 1988)$ observou que existiam imperfeições transacionais -assimetrias entre mercados - e estruturais - relacionadas diretamente ao poder exercido pelo governo. $O$ resultado de seus estudos ficou conhecido como Paradigma Eclético, que visa a explicar a habilidade e a propensão das empresas para entrar em novos mercados, bem como a razão pela qual elas optam por produzir localmente em detrimento de exportar, licenciar ou implantar subsidiárias. Os motivos elencados pelo autor são as vantagens específicas, de propriedade, de localização e de internalização (conhecido pelo acrônimo OLI - ownership, location, internalization), decorrentes das imperfeições de mercado (DUNNING, 1980; 1988; VIEIRA, 2009).

Os estudos dos pesquisadores da Escola de Uppsala iniciaram na década de 1960, com o pesquisador Sune Carlson, e questionavam o processo de internacionalização das empresas suecas (BJÖRKMAN; FORSGREN, 2000). Em 1975, Johanson e Wiedersheim-Paul deram continuidade aos estudos de Carlson e, com base em pesquisas empíricas, determinaram que a internacionalização é consequência de uma série de decisões incrementais, baseadas na aquisição de experiência nos negócios e no aprendizado sobre novos mercados e culturas (JOHANSON; VAHLNE, 1977; JOHANSON; WIEDERSHEIM-PAUL, 1975). Logo, em razão da falta de conhecimento e da aversão à incerteza, as empresas começavam a exportar para países com proximidade cultural e, com base na aprendizagem, expandiam sua atuação ao redor do globo, utilizando 
modos de entrada que exigiam maior grau de comprometimento com o exterior. Esse modelo de internacionalização posteriormente ficou conhecido como U-model (JOHANSON; VAHLNE, 1977, 1990).

A aprendizagem sobre mercados externos e operações é capaz de diminuir a incerteza e propiciar maior envolvimento internacional (JOHANSON;VAHLNE, 1977). No entanto, ela não é decorrente apenas das atividades da empresa, podendo advir das redes de relacionamento. Assim, o conhecimento baseado na experiência pode decorrer de interações de negócios, por meio do compartilhamento de informações com empresas ligadas pela rede, seja ela formal ou informal (JOHANSON; VAHLNE, 1990, 2003).

As redes de relacionamento são foco de estudo dos pesquisadores nórdicos desde o final da década de 1980. Johanson e Mattsson (1988) direcionaram sua atenção para o processo de internacionalização como resultado da sua posição numa rede. Logo, propuseram um modelo de internacionalização de empresas com base no grau de internacionalização da rede em que a empresa estava inserida. De forma sintética, o modelo é composto por quatro estágios: (1) the early starter - no qual as empresas e a rede têm pouco envolvimento com competidores e fornecedores no exterior, exportando via agentes; (2) the lonely international - as empresas adquirem conhecimentos e experiência no exterior, ficando altamente internacionalizadas, mas a rede ainda pouco internacionalizada; (3) the late starter - neste estágio, a rede é caracterizada por um alto nível de internacionalização, mas as empresas atuam no exterior por meio de atores externos à empresa; e (4) international among others - empresas altamente internacionalizadas que estão conectadas com várias redes internacionais, utilizando conhecimentos prévios da empresa e da própria rede, facilitando a obtenção de recursos (AMAL; FILHO, 2010).

Dunning (2000) apontou a relevância da integração das teorias econômica e comportamental para melhor compreender a empresa multinacional e o investimento direto externo. Em seu estudo, apresentou a complementaridade de diversas teorias, tendo o paradigma eclético como um modelo analítico comum, capaz de integrar essas perspectivas. Atualmente, percebe-se que dificilmente é possível explicar o processo de internacionalização por completo com base em apenas um viés teórico, sendo necessário selecionar de que forma cada lente teórica é capaz de explicar parte do fenômeno.

Tratando-se de economias emergentes, é importante considerar também os aspectos extrafirma para compreender os fenômenos relacionados aos negócios internacionais, dentre eles 
o ambiente institucional (MAIS; AMAL, 2009; PENG et al., 2009). Uma vez que nenhuma empresa está imune ao ambiente institucional em que está inserida, é necessário analisar o papel das instituições na internacionalização das empresas (PENG, 2002).

\subsection{VISÃO BASEADA EM INSTITUIÇÕES}

Scott (1995, p. 33) define instituições como: "estruturas cognitivas, regulatórias e normativas e atividades que fornecem a estabilidade e significado ao comportamento social". De acordo com DiMaggio e Powell (1983), o domínio cognitivo baseia-se na premissa da inacessibilidade do conhecimento, induzindo o indivíduo a adotar padrões de comportamento semelhantes aos do restante da população. Já o domínio regulatório, segundo os autores, consiste nos regramentos aos quais os agentes estão sujeitos, sejam essas normas de origem governamental, social, comercial, organizacional, cultural ou outra qualquer. Por último, o domínio normativo refere-se aos fatores relacionados à cultura, estando inseridos os valores, as normas, os costumes e as crenças.

North (1990) resume que as instituições são as regras do jogo e as organizações são os jogadores. Essas regras, sejam elas de ordem objetiva ou subjetiva, consciente ou inconsciente, de natureza política, econômica, social, jurídica ou cultural, criam o domínio que legitima ou não aqueles que estão contidos nele.

Segundo Peng et al. (2009), as nações possuem diferentes riscos políticos (como corrupção e regime regulatório) que podem afetar a estabilidade dos seus mercados. As instituições têm como função reduzir as incertezas dos diferentes atores, condicionando normas dominantes de comportamentos e definindo limites (PENG et al., 2009).

De acordo com North (1990), as instituições podem ser classificadas como formais (composta por leis, regulamentações e regras) e informais (normas, cultura e valores). Peng et al. (2009), baseados nos estudos de North (1990), postularam que, nas situações em que as restrições formais não estão claras, as restrições informais irão desempenhar um papel maior na redução da incerteza, fornecendo orientações e conferindo legitimidade para os gestores.

Hoskisson et al. (2000) apresentam a relevância da visão baseada em instituições na análise da estratégia. Juntamente com a sólida visão baseada na indústria (defendida por Michael Porter) e a visão baseada em recursos (ancorada nos estudos de Jay Barney e Birger Wernerfelt), a 
abordagem institucional auxiliaria a compreender os negócios internacionais nos países emergentes, uma vez que nestas regiões as diferenças institucionais são mais salientes (PENG, 2002; PENG; WANG; JIANG, 2008; PENG et al., 2009). Ao tratar as instituições como variáveis independentes, o foco de análise passa a ser na interação entre as instituições e organizações, tendo como resultado as escolhas estratégicas que podem ser reflexo de uma restrição formal ou informal de um arranjo institucional específico, como exposto na Figura 1 (PENG, 2002).

Figura 1: Instituições, organizações e escolhas estratégicas

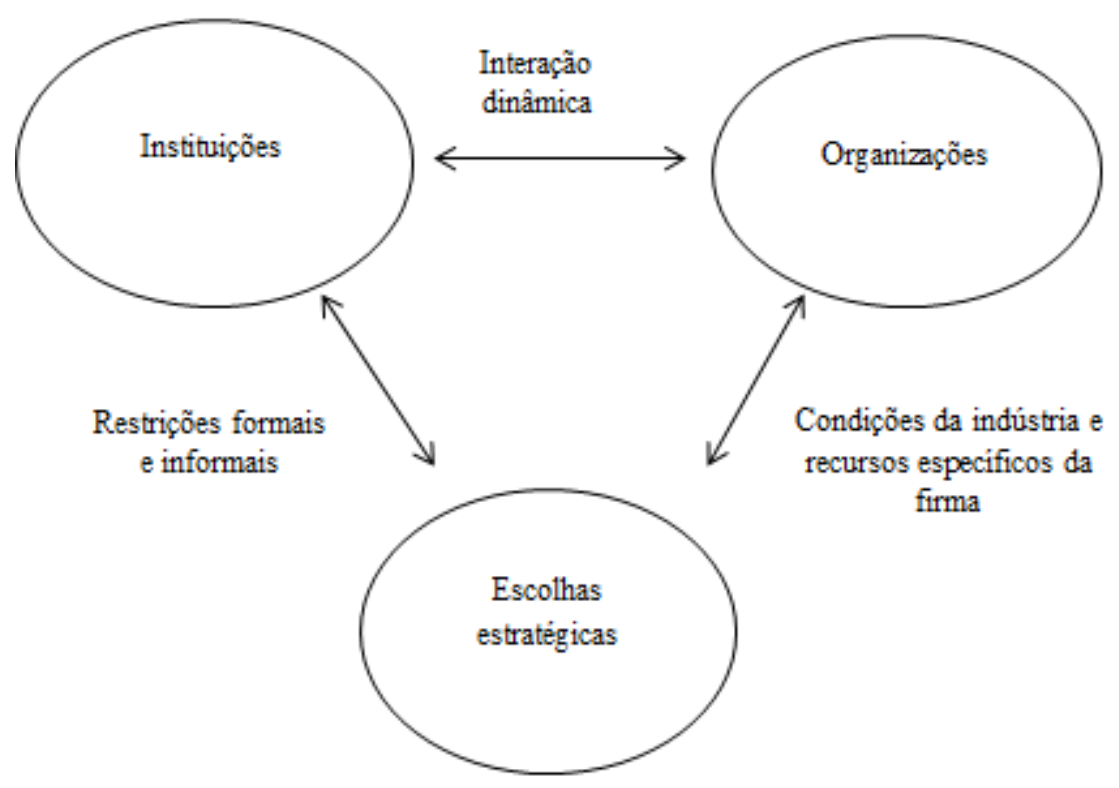

Fonte: Peng, 2002, p. 253.

Conforme Mais e Amal (2009, p. 1) "quando uma nação ou sociedade assume um determinado quadro institucional, ela cria condições mais favoráveis para o desenvolvimento de determinadas atividades e estruturas organizacionais em detrimento de outras". Logo, os autores entendem que as instituições podem exercer uma influência direta na escolha de estratégias, como a internacionalização. De acordo Mais e Amal (2009), os arranjos legais e governamentais, bem como as instituições informais, dão suporte na definição de uma economia. Esses elementos institucionais podem influenciar as estratégias corporativas, alterando assim o funcionamento dos negócios, determinando o seu grau de inovatividade, nível de empreendedorismo, a orientação para o mercado externo e o nível de desenvolvimento tecnológico. 
Como este artigo visa a compreender a influência das instituições no desenvolvimento do setor vitivinícola da Serra Gaúcha com vistas ao mercado internacional, a seguir, apresenta-se a metodologia utilizada para atingir tal objetivo.

\section{METODOLOGIA}

Esta foi uma pesquisa qualitativa de cunho descritivo, pois a questão de pesquisa visava a interpretar as relações causais entre as teorias de internacionalização e a visão baseada em instituições (COLLIS; HUSSEY, 2005). Buscou-se relacionar o referencial teórico com as evidências empíricas coletadas e dados secundários obtidos no Instituto Brasileiro do Vinho (Ibravin) e no Anuário Vinhos do Brasil - 2012.

Em relação à técnica utilizada, adotou-se o estudo de caso para que fosse possível realizar um exame mais extenso do fenômeno (YIN, 2005). A escolha das vinícolas participantes deu-se por conveniência, uma vez que foram selecionadas empresas integrantes do projeto Wines of Brasil na Serra Gaúcha. Para compor o estudo de caso, realizou-se um protocolo do caso, elucidando o objetivo da pesquisa, o embasamento teórico para ancorá-la, assim como o plano de coleta de dados e dos procedimentos operacionais de campo (DUBÉ; PARÉ, 2003).

Optou-se pelo uso de entrevistas semiestruturadas, além do uso de materiais disponíveis nos sítios eletrônicos da instituição e das vinícolas participantes. A triangulação dos dados permite realizar análises mais cuidadosas, uma vez que há diferentes fontes de informação e auxilia a validar a pesquisa (DUBÉ; PARÉ, 2003). Com base na literatura apresentada no capítulo anterior, foram determinadas categorias de análise para a elaboração do roteiro de entrevista. Realizaram-se seis entrevistas (ver Quadro 1) e, como critério de escolha dos participantes da pesquisa, buscaram-se colaboradores envolvidos diretamente no projeto Wines of Brasil. 
Quadro 1: Informações gerais das entrevistas

\begin{tabular}{|c|l|l|c|}
\hline Entrevistado & \multicolumn{1}{|c|}{ Empresa } & \multicolumn{1}{|c|}{ Cargo } & Data \\
\hline 1 & IBRAVIN & Diretor Técnico & $18 / 01 / 2012$ \\
\hline 2 & Wines of Brasil & Gerente de Exportação & $18 / 01 / 2012$ \\
\hline 3 & Vinícola Aurora & Supervisor de Exportação & $18 / 01 / 2012$ \\
\hline 4 & Vinícola Salton & Coordenador de Exportação & $26 / 01 / 2012$ \\
\hline 5 & Vinícola Miolo & $\begin{array}{l}\text { Gerente de Relações } \\
\text { Internacionais }\end{array}$ & $07 / 02 / 2012$ \\
\hline 6 & Vinícola Basso & Gerente de Exportação & $07 / 02 / 2012$ \\
\hline
\end{tabular}

Fonte: Elaborado pelos autores, 2012.

Por último, a unidade de análise deste estudo é o Projeto Wines of Brasil - vinícolas e entidades - uma vez que esse projeto representa a integração de diversas instituições para um esforço comum de desenvolver o setor vitivinícola brasileiro. Para a análise dos dados, foram utilizados os resumos elaborados pelos autores, as gravações das entrevistas, além dos materiais disponíveis nos sítios eletrônicos dos participantes do estudo. De acordo com Bardin (1979), a análise qualitativa é aplicável no intuito de elaborarem-se deduções específicas sobre acontecimentos, na busca de inferências mais dirigidas, baseadas em índices que a amparem.

\section{RESULTADOS}

\subsection{A INDÚSTRIA DE VINHOS NO RIO GRANDE DO SUL E O PROJETO WINES OF BRASIL}

A indústria vitivinícola apresenta relevância econômica para o estado do Rio Grande do Sul. Introduzida pelos imigrantes italianos a partir de 1875, que se estabeleceram em uma região topográfica hostil - composta por morros, terrenos íngremes e pedregosos - e com um clima severo - caracterizado pelo frio intenso no inverno -, a qual se tornou propícia para o cultivo da uva e a produção do vinho. Farias (2006) divide a história da cultura da uva e da produção do vinho em quatro períodos: (1) de 1875 a 1915, quando a produção era para o consumo familiar; (2) de 1915 até a década de 1960, marcada pela comercialização regional e nacional; (3) décadas de 1960 e 1970, consolidação de vinícolas por empresas estrangeiras como Martini, Chandon, 
Maison Forestier, Chateau Lacavee; e (4) a partir da década de 1990, profissionalização das vinícolas gaúchas e início da internacionalização do setor.

A maior parte da produção brasileira de uvas e derivados da uva e do vinho é destinada ao mercado interno. Na pauta exportadora, o principal produto, em volume, é o suco de uva, com $15 \%$ do total produzido destinado ao mercado externo. Apesar de ser o quinto maior produtor do Hemisfério Sul, apenas $1 \%$ dos vinhos produzidos no Brasil são comercializados fora do país (IBRAVIN, 2012a; IBRAVIN, 2012b).

O setor tem enfrentado a concorrência internacional no mercado interno em função das crescentes importações de vinhos (98,7\% de acréscimo em 2011 comparado com o volume importado em 2004), principalmente oriundos do Chile, da Argentina, da Itália e de Portugal. Logo, para enfrentar esse cenário nada favorável para as vinícolas brasileiras, as empresas têm buscado a ampliação das atividades internacionais como uma alternativa estratégica de sobrevivência no próprio mercado doméstico (IBRAVIN, 2012).

Com a programação de eventos internacionais como os Jogos Olímpicos e a Copa do Mundo de Futebol, além de todo desenvolvimento econômico dos últimos anos, o país tem chamado atenção dos principais expoentes mundiais. O projeto Wines of Brasil favoreceu-se deste cenário e realizou diversas ações de promoção comercial no exterior em 2011 (IBRAVIN, 2012b). De acordo com os entrevistados, as dificuldades enfrentadas pelo vinho brasileiro no mercado internacional não estão relacionadas à qualidade, mas sim ao chamado custo Brasil, envolvendo elevados tributos, infraestrutura precária, ausência ou existência de tratados bilaterais, ou carência de linhas de financiamento.

O Projeto Setorial Integrado Wines of Brasil tem sua origem declarada no ano de 2002, por meio de um consórcio de exportação organizado pela Federação das Indústrias do Estado do Rio Grande do Sul (FIERGS). Naquele momento, era formado por seis vinícolas que se agruparam, por intermédio da FIERGS, visando a iniciar o processo de internacionalização por meio de um planejamento, com estudos de mercado e desenvolvimento de experiências iniciais no mercado externo, principalmente por intermédio de cursos, reuniões, feiras e eventos internacionais. Com o apoio da Agência Brasileira de Promoção à Exportação e Investimentos (APEX), o consórcio de exportação tornou-se um projeto setorial integrado por meio de um acordo com o Instituto Brasileiro do Vinho (IBRAVIN), tendo como objetivo inicial promover o vinho brasileiro no mercado internacional. O apoio institucional do Wines of Brasil para as vinícolas participantes inclui subsídio 
financeiro para a exposição da empresa em eventos internacionais, estudos sobre os mercadosalvo, treinamentos relacionados ao mercado internacional e acesso aos convênios com prestadores de serviço para envio de amostras, desembaraço aduaneiro, passagens aéreas, entre outras atividades relacionadas ao mercado externo (WINES OF BRASIL, 2012).

O serviço de inteligência da APEX realizou uma análise do volume importado de vinhos e a importância destes países como formadores de opinião, portanto, a equipe do Wines of Brasil e os gestores das vinícolas selecionaram os seguintes mercados-alvo: Estados Unidos, Canadá, Holanda, Alemanha, Inglaterra, Suécia, Polônia e Hong Kong. Esses são os mercados onde planejam desenvolver maiores esforços do projeto no tocante à participação em feiras, rodadas de negócio e promoção comercial.

No entanto, cabe a cada vinícola determinar os países nos quais tem interesse em desenvolver negócios. Segundo o entrevistado da Salton, a vinícola analisa os seguintes fatores para determinar os mercados de atuação: possibilidade de expansão futura, valorização da imagem da vinícola pela presença no mercado do país (tradição de mercado), consumidores tradicionais, boas relações comerciais com o Brasil e ações conjuntas com o projeto Wines of Brasil. Com isso, os mercados da Salton e da iniciativa da Wines of Brasil são praticamente os mesmos (a vinícola adiciona a Suíça na lista original). Em relação à vinícola Aurora, foram mencionados os Estados Unidos, Holanda e Finlândia. Embora muitos critérios de seleção se assemelhassem entre os utilizados pelas vinícolas e pelo projeto, reforçando um padrão de comportamento, observa-se uma força institucional das maiores vinícolas em nortear as escolhas dos mercados do grupo. Ainda, todas as vinícolas entrevistadas afirmaram que, em função do apoio financeiro do projeto Wines of Brasil (aluguel e montagem da estrutura nas feiras comerciais) apenas para os mercados previamente selecionados, muitas vinícolas preferem atuar onde existe esse benefício.

Em 2011, o Wines of Brasil contava com 37 vinícolas e tinha como metas um maior reconhecimento do vinho nacional e o aumento do volume de exportações e do número de exportadores, segundo a gerente geral do projeto. As demais entidades atuam como capacitadores - ou parceiros operacionais, como chama o representante do IBRAVIN - entidades de desenvolvimento empresarial como o Serviço Brasileiro de Apoio às Micro e Pequenas Empresas (SEBRAE), para a capacitação das empresas por meio das melhores práticas agrícolas e de elaboração, FIERGS, Secretaria do Desenvolvimento e Promoção do Investimento Estado do Rio 
Grande do Sul (SDPI-RS), do setor vinícola (União Brasileira de Vitivinicultura - UVIBRA - e Associação Brasileira de Enologia - $A B E$ ), além da Empresa Brasileira de Pesquisa Agropecuária (EMBRAPA) e universidades da região Sul do Brasil. Além disso, os entrevistados citaram que o governo federal exerce papel preponderante ao investir no projeto, principalmente por intermédio do apoio financeiro da APEX, do Ministério das Relações Exteriores e por meio das e Embaixadas Brasileiras no exterior.

A representante do Wines of Brasil reforça que, atualmente, ou a vinícola brasileira se internacionaliza ou ela perderá competitividade, inclusive no mercado doméstico, pois o mercado internacional gera um aprendizado imensurável, fato este que é de amplo reconhecimento por parte dos representantes das vinícolas conforme os depoimentos coletados. A representante da vinícola Aurora suporta essa visão ao mencionar que as vinícolas têm buscado internacionalizar-se como uma alternativa para escoar a produção e diversificar o mercado, mesmo que, segundo o representante da vinícola Salton, as exportações representem somente $1 \%$ do faturamento da empresa. Contudo, o benefício direto tem sido a melhoria da imagem da marca do vinho, principalmente no mercado nacional.

Segundo os entrevistados, o setor vitivinícola brasileiro não sofre limitações tecnológicas perante o chamado Velho Mundo do vinho (países tradicionais e precursores na produção do vinho, como França, Itália, Espanha e Portugal), possuindo os equipamentos mais modernos da indústria e processos de produção bastante qualificados. De acordo com o representante do IBRAVIN, a restrição do vinho nacional é originária, na verdade, pela topografia desfavorável e pelo sistema de transporte, que não propicia as condições ideais para a obtenção do melhor vinho.

A gerente geral da Wines of Brasil reforça que a maior dificuldade do projeto é o desconhecimento dos consumidores estrangeiros do vinho brasileiro, diferentemente da cachaça, por exemplo, um produto tipicamente nacional e reconhecido no âmbito internacional. Entretanto, a superação desse desafio, segundo resposta unânime dos entrevistados, vem gerando benefícios perceptíveis não somente para o mercado externo, mas também para o mercado doméstico, pois o consumidor brasileiro é de certa forma, preconceituoso com os vinhos nacionais, caracterizando os vinhos importados como de melhor qualidade do que aqueles produzidos no Brasil. Portanto, o reconhecimento internacional cria uma expectativa de que essa 
imagem do consumidor se altere, de maneira até a incrementar o consumo per capita de vinho, visto que esse é outro obstáculo da indústria, segundo o representante do IBRAVIN.

Para as vinícolas participarem do projeto, existem regras definidas entre as instituições. No entanto, não existiu uniformidade nas respostas fornecidas pelos entrevistados, demonstrando que as normas não são de senso comum ou, até mesmo, formalizadas, tanto entre os participantes quanto entre os reguladores. Para a representante da vinícola Aurora, o interessado deve: submeter os vinhos a um comitê formado por doze enólogos que assegurem a qualidade do produto; ter, no mínimo, uma lista de preços formatada; e um profissional que se comunique em inglês. A entrevistada resume que a vinícola deve apresentar uma qualidade mínima do produto e do serviço oferecidos. Enquanto que, na visão do representante da vinícola Salton, não existem restrições para participar do projeto, até mesmo porque ele é aberto para as pequenas empresas. Contudo, aquelas que aderirem ao projeto devem participar das reuniões propostas e apresentar um vinho com um mínimo de qualidade, mas deverá ser aprovado pelo próprio mercado. Segundo as informações disponíveis no sitio eletrônico do projeto, as exigências para se integrarem ao projeto são: a definição de um representante para responder ao projeto; o envolvimento nas ações de adequação e promoção comercial; e o fornecimento de informações sobre a vinícola (WINES OF BRASIL, 2012), o que corrobora parcialmente os depoimentos do entrevistado da Salton e da Aurora.

O relato da gerente geral do Wines of Brasil é de que não existem restrições aos interessados em participar do Wines of Brasil, desde que a vinícola tenha o interesse de comercializar vinhos finos no mercado externo. Ela salienta que é fornecida uma consultoria in company durante dez meses e que a própria troca de informações entre as vinícolas gera um nivelamento espontâneo, criando uma competitividade sadia, apesar das empresas estarem em estágios diferentes de internacionalização. Além da consultoria, existe o Programa Primeira Exportação (PPE) e um trabalho focado que aborda a legislação de cada país-destino da exportação. A entrevistada da vinícola Basso confirma a validade do treinamento fornecido aos participantes, como capacitações para participar dos eventos internacionais, e também com o trabalho burocrático da exportação como documentação e envio de amostras.

Considerando todos os relatos, observa-se que o projeto proporcionou o alcance a todas vinícolas participantes, independentemente do porte. Daquelas que iniciaram sua atuação juntamente com o projeto em 2002, algumas já desfrutam de um estágio mais avançado de 
internacionalização, como formação de parcerias internacionais. Porém, mesmo para os casos de início tardio, o Wines of Brasil possibilitou atingir mercados até então inimagináveis, participando de feiras e eventos internacionais que têm custos elevados e exigem um alto grau de preparação técnica, o que não seria viável para as empresas de forma independente. Nesse quesito, a troca de informações e a integração entre os participantes são propulsores do processo, criando uma visão única de uma relação sinérgica para o mercado externo. De acordo com a entrevistada da vinícola Basso, o projeto Wines of Brasil auxilia as vinícolas também por meio da organização das rodadas de negócios direcionadas aos objetivos de cada empresa e eventos de marketing, como degustação de vinhos com a imprensa em um momento anterior às feiras.

\subsection{O CASO À LUZ DA TEORIA}

Ao trazer à tona a teoria institucional para o cenário do projeto previamente descrito, observam-se diversos retratos observados pelos autores seminais. DiMaggio e Powell (1983) dão significância ao isomorfismo organizacional e, conforme as narrativas dos entrevistados das vinícolas Aurora e Salton, percebe-se a tradução de um comportamento homônimo ao notar que elas seguem a mesma estratégia de internacionalização que o projeto Wines of Brasil, com poucas variações, buscando uma legitimidade na decisão tomada e uma redução do risco em um cenário caracterizado por incertezas.

Além disso, a teoria comportamental da Escola de Uppsala não se aplica a esse processo de internacionalização, pois as exportações das vinícolas brasileiras não foram motivadas pelo baixo distanciamento cultural, geográfico e psíquico, como a escola nórdica postula ( JOHANSON;WIEDERSHEIM-PAUL, 1975; JOHANSON; VAHLNE, 1977). No caso da vinícola Basso, participante do Projeto Primeira Exportação da Wines of Brasil, seu mercado inicial foi a Noruega, em função de contatos realizados em feiras do setor. Na seleção dos mercados-alvo, não constam países na América Latina ou Portugal que, seguindo o viés teórico-comportamental, seriam os países com menor distância psíquica. Entretanto, a similaridade de mercados e o estágio evolutivo superior de países como Argentina, Uruguai e, principalmente, Chile, não permitiram que o vinho brasileiro fosse competitivo nesses mercados, segundo informado pela gerente geral do Wines of Brasil. A escolha dos mercados-alvo está fundamentada no volume de vinho importado e o valor gasto pelo consumidor com vinhos, uma vez que o produto brasileiro não é considerado barato. 
$\mathrm{Na}$ perspectiva das redes de relacionamento proposta por Johanson e Mattsson (1988), pode-se inferir que o projeto Wines of Brasil seja caracterizado com uma associação em rede que direciona seus esforços para a internacionalização. De forma geral, a rede ainda estaria no primeiro estágio - the early starter - pois a maioria das empresas tem pouco envolvimento com competidores e fornecedores no exterior, atuando apenas via exportação. Casos isolados como a vinícola Miolo estão no segundo estágio - the lonely international -, mas a rede ainda está pouco internacionalizada.

A teoria econômica também deixa lacunas nessa análise do caso, visto que, como mencionado pelos entrevistados das vinícolas Salton e Miolo, as exportações têm pouca representatividade. O entrevistado da Salton salientou que a vinícola nem buscava exportar e, somente a partir de 2010, criou um departamento de comércio internacional, visto que, até então, as exportações ocorriam por iniciativa dos compradores estrangeiros. A representante da vinícola Aurora, que é a empresa mais experiente no mercado externo (atuava no mercado internacional anteriormente ao projeto Wines of Brasil), corrobora essa visão e cita inclusive que, muitas vezes, as vendas no mercado externo exigem investimentos que somente são realizados devido ao aumento das vendas no mercado doméstico. Até mesmo a maior exportadora do projeto, a vinícola Miolo, conta com apenas 5\% do seu faturamento nas vendas de exportação.

Com base esses relatos, descaracteriza-se a teoria dos custos de transação, teoria de internalização e o paradigma eclético (DUNNING, 1980; 1988; WILLIAMSON, 1985) em relação ao mercado externo. Os elementos localização e propriedade do paradigma eclético puderam ser percebidos nos depoimentos dos entrevistados em relação à expansão das empresas às demais regiões do Rio Grande do Sul e de outros estados, por meio do acesso a recursos de localização específica (terroir). O entrevistado da Salton comentou a recente aquisição da empresa de 700 hectares na campanha gaúcha para desenvolver a produção de alguns tipos de uvas, cuja produção é mais adequada naquela região. O grupo Miolo atua na campanha gaúcha por meio da Seival Estate e Almadén, nos Campos de Cima da Serra (RS), como a RAR (parceria com Raul Anselmo Randon) e no Vale do São Francisco (BA), com a vinícola Ouro Verde.

Em relação ao governo, ele remete justamente ao fator integrativo do setor por meio das entidades designadas para promover o projeto, tais como APEX, IBRAVIN e o próprio Wines of Brasil. É fato o quanto essas instituições aproximaram as vinícolas em prol de um objetivo comum, caracterizando, segundo Scott (1995), os domínios normativo e regulatório. Os entrevistados 
mencionaram uma tímida atuação do governo estadual nas ações de promoção internacional, apesar de o IBRAVIN informar sobre a existência do Fundo de Desenvolvimento de Vitivinicultura (Fundovitis).

O domínio normativo é caracterizado pelo agrupamento das vinícolas por meio de uma mesma cultura, valores, crenças, normas e costumes, corroborando o estudo de DiMaggio e Powell (1983). No entanto, a grande dificuldade foi extirpar a desconfiança e o sentimento de competição entre as famílias produtoras, ultrapassar as diferenças socioeconômicas, preservando valores familiares (que são reconhecidos comercialmente, segundo a representante do Wines of Brasil), e promover a profissionalização do setor.

Diante de um cenário de tamanha pressão e volatilidade, as organizações competem não apenas por recursos e por participação de mercado, como também pela legitimidade institucional que crie uma identidade de aceitação do ambiente. Entretanto, como consequência, a convergência progressiva para um padrão de homogeneidade entre as empresas torna-se evidente (MEYER; ROWAN, 1977; DIMAGGIO; POWELL, 1983). Todavia, no caso em estudo, a percepção sobre o tema é mais visível ainda, pois existe uma instituição formalizada que congrega todas as organizações e entidades.

O IBRAVIN foi criado com o objetivo de integrar a cadeia produtiva do setor de vitivinicultura, congregando as principais entidades da cadeia produtiva de uva e vinho, ordenando institucionalmente o setor vitivinícola (IBRAVIN, 2012a; IBRAVIN, 2012b). De acordo com os entrevistados, a instituição atua de forma inquestionável na união dos produtores locais em busca do mercado externo. Segundo Mais e Amal (2009), as instituições podem auxiliar no compartilhamento de informações sobre mercado e até na mobilização para a implantação de políticas de incentivo.

Em relação ao domínio regulatório, não se observa a mesma sintonia entre os participantes. Como mencionado nos relatos dos entrevistados, não houve um discurso uníssono a respeito das regras que norteiam as exigências para uma vinícola participar do projeto Wines of Brasil. Isso é elemento que se sugere que seja analisado pelo IBRAVIN ao incluir novos associados anualmente no programa Wines of Brasil, pois a dimensão regulatória trata não somente das normativas oriundas do governo, porém de todas que regem a sociedade (DIMAGGIO; POWELL, 1983). Caso as regras não sejam claras, transparentes, de conhecimento universal e aceito por 
todos, a sua legitimidade e, por conseguinte, a da instituição, do grupo ou do projeto, como é o caso, estarão sob risco de serem questionados.

A Figura 2 foi desenvolvida com base nos estudos de Peng (2002) e representa a caracterização da interação desenvolvida entre as instituições relacionadas ao projeto Wines of Brasil, sob o comando e articulação do IBRAVIN na escolha estratégica de ampliar o mercado de atuação das vinícolas participantes ao exterior. Algumas condições da indústria como a competição dos vinhos importados no mercado nacional, a grande capacidade de produção atrelada aos recursos disponíveis e a qualidade do vinho corroboraram essa decisão. No entanto, as restrições formais como qualidade mínima exigida aos participantes não estão claramente determinadas aos participantes do projeto. Sabe-se que existem certificações necessárias para ingressar em alguns mercados, mas não são exigências para as empresas aderirem ao projeto, uma vez que o mercado faz a seleção.

Figura 2: Instituições, organizações e escolhas estratégicas do Projeto Wines of Brasil

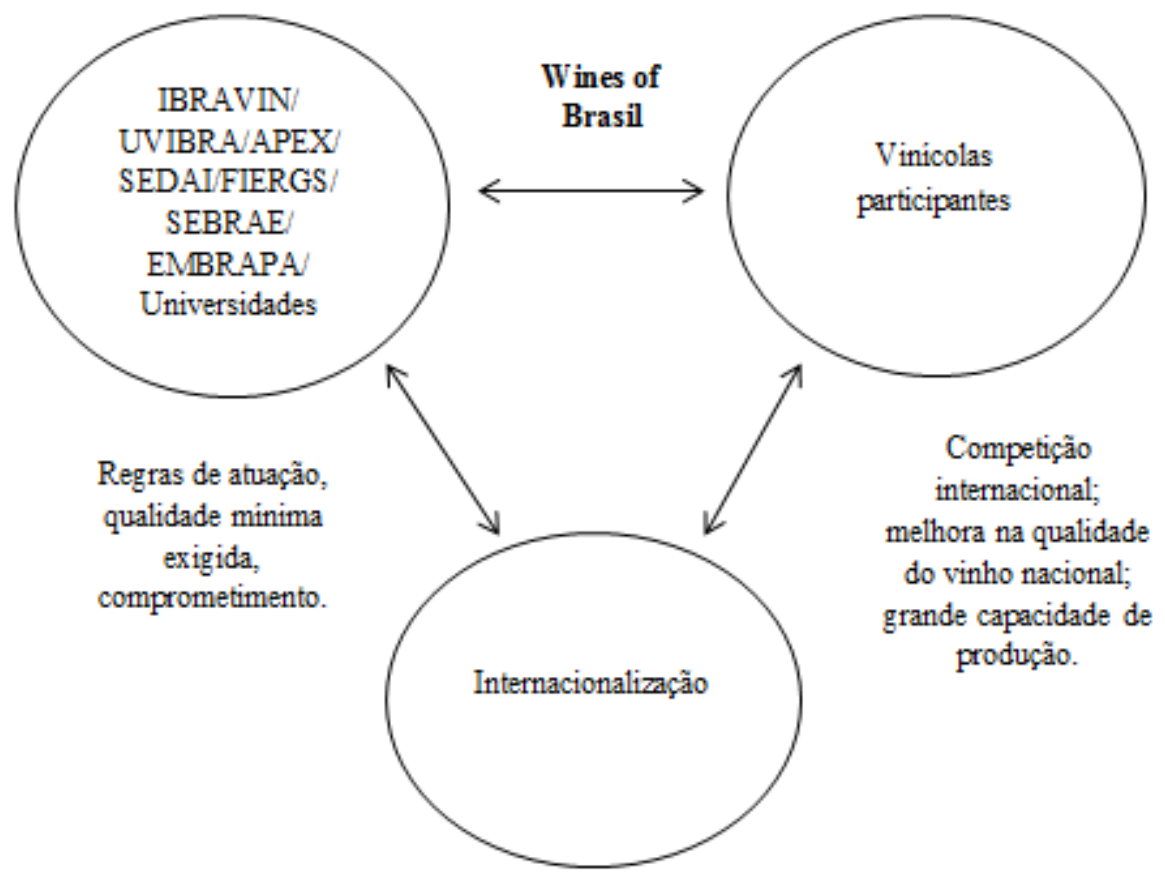

Fonte: Adaptado de Peng, 2002.

De acordo com Mais e Amal (2009), os arranjos institucionais podem influenciar as estratégias corporativas. Percebe-se que a formação do projeto Wines of Brasil alterou a dinâmica dos negócios dos produtores de vinhos finos da Serra Gaúcha. Mesmo as empresas que já 
atuavam no mercado externo foram beneficiadas pelo projeto e ampliaram seus esforços. Enquanto que as empresas que não planejavam exportar perceberam no projeto uma oportunidade de diversificar mercados e melhorar a imagem do vinho no mercado interno, em função do reconhecimento internacional.

\section{CONSIDERAÇÕES FINAIS}

$\mathrm{Na}$ busca de compreender a influência da instituição no processo de internacionalização das vinícolas da Serra Gaúcha, o presente estudo apresentou brevemente o setor vitivinícola do Rio Grande do Sul, destacando os principais polos produtores e sua expansão produtiva pelo Brasil. Constata-se que existem poucas fontes disponíveis acerca do tema, concentrando-se nos materiais desenvolvidos pelo IBRAVIN, como os relatórios da instituição e o Anuário dos Vinhos do Brasil.

Em relação ao processo de inserção internacional das vinícolas da Serra Gaúcha, verificou-se que as teorias de internacionalização deixaram lacunas em relação às ações realizadas pelas vinícolas da região, o que corrobora os estudos de Fleury e Fleury (2007). No entanto, acredita-se que a maior contribuição desse artigo encontra-se na abordagem complementar da visão baseada em instituições que vem sendo construída a partir dos estudos de Peng (2002).

O estudo permitiu constatar, ao longo da revisão da literatura, da análise documental e das entrevistas realizadas, o papel do IBRAVIN como articulador do processo de integração das vinícolas visando ao mercado externo; já o projeto Wines of Brasil foi o marco inicial das ações internacionais de muitas vinícolas, inclusive aquelas de grande porte. Houve benefícios com a participação no projeto, tendo em vista que muitas empresas só tiveram acesso às feiras internacionais e rodadas de negócio pela articulação do IBRAVIN junto aos órgãos financiadores e representantes do governo federal no exterior, como as Embaixadas Brasileiras no exterior. Ainda, o projeto Wines of Brasil tem aproveitado a imagem positiva do Brasil no mercado externo e o interesse pelo país em função dos eventos esportivos para desenvolver uma série de ações promocionais do vinho brasileiro. Nesse contexto, observa-se a importância do ambiente institucional, no nível do país, como elemento positivo para a internacionalização. Logo, confirma- 
se que o projeto influenciou significativamente na decisão das vinícolas no processo de internacionalização, seja no subsídio à participação em feiras no exterior, na capacitação das vinícolas para as atividades de comércio exterior, ou no desenvolvimento de estudos de mercado e rodadas de negócio.

Entretanto, assim como o ambiente institucional favorece os participantes no processo de internacionalização, sua incipiência também gera a percepção de fatores que devem ser aprimorados em prol de um maior ganho sinérgico entre os integrantes do projeto Wines of Brasil. No domínio normativo, percebe-se a necessidade de aproximar ainda mais os representantes de cada vinícola, mitigando sentimentos de desconfiança ou de competição, além de agregar profissionalismo na gestão organizacional. Na dimensão regulatória, torna-se preponderante a clarificação e disseminação das regras e normas que norteiam o projeto, proporcionando maior credibilidade ao produto brasileiro e, ao mesmo tempo, tornando-o mais atrativo para novos entrantes.

Este estudo apresenta como limitações: (a) ter entrevistado quatro vinícolas do projeto Wines of Brasil da Serra Gaúcha, que possuem boa atuação nos projetos desenvolvidos pelo grupo; (b) não foi possível avaliar a força institucional que define o poder decisório dentro do projeto Wines of Brasil, tanto em nível das vinícolas quanto das demais entidades; e (c) os entrevistados informaram haver uma atuação tímida do governo do estado na promoção do setor e não foram ouvidos, no estudo, responsáveis do governo que pudessem relatar e avaliar essa atuação.

A partir dos resultados e das próprias limitações, recomenda-se que novos estudos no tema abordem: um número maior de vinícolas, com variadas características de estrutura e envolvimento com o projeto, a fim de verificar novos pontos de discussão e moderação; uma pesquisa focando a organização interna do projeto Wines of Brasil, a fim de avaliar seu sistema de gestão e seus processos decisórios; a ampliação das análises sobre as ações das instituições de governo nas relações com o setor de vitivinicultura; e avaliar os resultados das diferentes ações do projeto Wines of Brasil. 


\section{INSTITUTION'S INFLUENCE IN THE INTERNATIONALIZATION OF THE WINERIES IN BRAZIL}

\section{ABSTRACT}

The rise on international competition in the wine market in Brazil made the Brazilian wineries analyzing their strategy and reach foreign market as an alternative to reinforce their competiveness. This case study aimed to comprehend the influence of institutions in the internationalization process of the wineries located at Serra Gaúcha (South region of Brazil). Therefore, we developed this study based on the interviews made with the managers of Wines of Brasil , 4 wineries participating in the project and also using secondary data. The project called Wines of Brasil developed by the Brazilian Wine Institute (Instituto Brasileiro do Vinho - IBRAVIN) and the Brazilian Trade and Investment Promotion Agency (Agência Brasileira de Promoção á Exportação e Investimentos - APEX) was developed to promote the Brazilian wines abroad. The institutional infrastructure developed by this project has fomented the internationalization of the wineries in the region, improving the image of Brazilian wines not only abroad, but also internally, through the increase on the amount exported as well as the number of wineries involved in the export's process. During our research of the theoretical foundations of internationalization, we realized that none of them could explain completely the actions developed by the wineries towards external market. Thus, the institutional based view assisted to understand the internationalization process in the Brazilian wineries, even though there are limitations on normative and regulatory structures where the players are involved.

Keywords: Internationalization. Wines of Brasil. Institutional based view.

\section{REFERÊNCIAS}

AMAL, M.; FILHO, A. R. F. Internationalization of small- and medium-sized enterprises: a multi case study. European Business Review, v. 22, n.6, p. 608-623, 2010.

BARDIN, L. Análise de conteúdo. Lisboa: Edições 70, 1979 
BJÖRKMAN, I.; FORSGREN, M. Nordic international business research: a review of its development. International Studies of Management \& Organization, v. 30, n.1, p. 6-25, 2000.

BUCKLEY, P.; CASSON, M. The future of multinational entreprise. London: Macmillan, 1976.

COASE, R. H. The nature of the firm. Economica, v. 4, n.16, p. 386-405, 1937.

COLLIS, J.; HUSSEY, R. Pesquisa em Administração. 2. ed. Porto Alegre: Bookman, 2005.

DIMAGGIO, P. J.; POWELL, W. W. The iron cage revisited: institutional isomorphism and collective rationality in organizational fields. American sociological review, v. 48, n. 2, p. 147-160, 1983.

DUBÉ, L.; PARÉ, G. Rigor in information system positivist case research: current practices, trends, and recommendations. MIS Quarterly, v. 27, n. 4, p. 597-635, 2003.

DUNNING, J. H. Toward an eclectic theory of international production: some empirical tests. Journal of International Business Studies, v. 11, n. 1, p. 9-31, 1980.

. The eclectic paradigm of international production: a restatement and some possible extensions. Journal of International Business Studies, v. 19, n. 1, p. 1-31, 1988.

. The eclectic paradigm as an envelope for economic and business theories of MNE activity. International Business Review, v. 9, n. 2, p. 163-190, 2000.

FARIAS, C. V. S. Formação da indústria vitivinícola do RS: da imigração italiana aos dias atuais. In: ENCONTRO DE ECONOMIA GAÚCHA, 4., Porto Alegre, RS, Brasil, 2008.

FLEURY, A.; FLEURY, M. T. Internacionalização das empresas brasileiras: em busca de uma abordagem teórica para os late movers. São Paulo: Atlas, 2007. p. 3-13.

HOSKISSON, R. E. et al. Strategy in emerging economies. Academy of Management Journal, v. 43, n. 3, p. 249-267, 2000.

HYMER, S. The international operation of national firms: a study of foreign direct investments. Cambridge: MIT Press, 1960.

IBRAVIN - Instituto Brasileiro do Vinho. Disponível em: <http://www.ibravin.org.br>. Acesso em: 7 fev. 2012a.

. Revista Anuário Vinhos dos Brasil. Rio de Janeiro: Pancrom, 2012b.

JOHANSON, J.; MATTSON, L. Internationalization in industrial systems: a network approach. In: HOOD, H., VAHLNE, J. (Eds.). Strategies in foreign competition. London: Croom Helm, 1988.

JOHANSON, J.; VAHLNE, J. The internationalization process of the firm: a model of knowledge development and increasing foreign market commitments. Journal of International Business Studies, v. 8, n.1, p. 23-32, 1977. 
The mechanism of internationalisation. International Marketing Review, v. 7, n. 4, p. 1124, 1990.

- Business relationship learning and commitment in the internationalization process. Journal of International Entrepreneurship, v. 1, n. 1, p. 83-101, 2003.

. The Uppsala internationalization process model revisited: from liability of foreignness to liability of outsidership. Journal of International Business Studies, Palgrave Macmillan, v. 40, n. 9, p. 1411-1431, 2009.

JOHANSON, J.; WIEDERSHEIM-PAUL, F. The internationalization of the firm? four swedish cases. Journal of Management Studies, v. 12, n. 3, p. 305-323, 1975.

MAIS, I.; AMAL, M. Instituições e internacionalização de empresas: proposição de um modelo. In: ENCONTRO DA ASSOCIAÇÃO NACIONAL DE PÓS-GRADUAÇÃO E PESQUISA EM ADMINISTRAÇÃO (EnANPAD), n. 33, 2009, São Paulo. Anais, São Paulo: ANPAD, 2009.

MARKOWITZ, H. Portfolio Selection. Journal of Finance, v. 7, n. 1, p.77-91, 1952.

MEYER, J.W; ROWAN, B. Institutional organizations: formal structure as myth and ceremony. American Journal of Sociology, n. 83, n. 2, p. 340-63, 1977

NORTH, D. C. Institutions, institutional change and economic performance. Cambridge: Cambridge University Press, 1990.

PENG, M. Towards an institution-based view of business strategy. Asia Pacific Journal of Management, v. 19, n. 2-3, p. 251-267, 2002.

PENG, M. et al. The institution-based view as a third leg for a strategy tripod. Academy of Management Perspectives, v. 23, n. 3, p. 63-81, 2009.

PENG, M.; WANG, D.; JIANG, Y. An institution-based view of international business strategy: a focus on emerging economies. Journal of International Business Studies, v. 39, n. 5, p. 920-936, 2008.

ROCHA, A.; SILVA, J. F.; CARNEIRO, J. Expansão internacional das empresas brasileiras: revisão e síntese. São Paulo: Atlas, 2007. p. 184-193.

SCOTT, W. R. Institutions and organizations. London: Sage, 1995.

VERNON, R. International investment and international trade in the product cycle. The Quarterly Journal of Economics, v. 80, n.2, p. 190, 1966.

VIEIRA, L. A contribuição de John Dunning aos estudos de negócios internacionais. Revista de Administração e Contabilidade da Unisinos, v. 6, n.4, p. 354-355, 2009. 
WELCH, L. S.; LUOSTARINEN, R. K. Internationalization: evolution of a concept. Journal of General Management, v. 14, n.2, p. 36-64, 1988.

WILLIAMSON, O. E. The economic institutions of capitalism. New York: Free Press, 1985.

WINES OF BRASIL. Projeto Wines of Brasil. Disponível em: <http://winesofbrasil.com>. Acesso em: 7 fev. 2012.

YIN, R. K. Estudo de caso: planejamento e métodos. 3 ed. Tradução E. Grassi. Porto Alegre: Bookman, 2005. 